\title{
Evaluation of clinical effectiveness of topical $0.2 \%$ glyceryl trinitrate, topical $2 \%$ diltiazem and their combination in the treatment of chronic anal fissure
}

\section{Rayamajhi BB', Khadka A2, Thakali K³ Thapa BB', Thapa N", Bhandari BB ${ }^{4}$}

'Bikash Bahadur Rayamajhi, Assistant Professor, Department of Surgery; ${ }^{2}$ Anjan Khadka, Assistant Professor, Department of Pharmacology; ${ }^{3}$ Kabir Thakali, Assistant Professor, Department of Accident and Emergency; ${ }^{1}$ Bikash Bikram Thapa, Assistant Professor, Department of Surgery; ${ }^{4}$ Narayan Thapa, Associate Professor, Department of Surgery; ${ }^{4}$ Bharat Bahadur Bhandari, Associate Professor, Department of Surgery; Nepalese Army Institute of Health Sciences (NAIHS), Sanobharyang, Kathmandu, Nepal.

\begin{abstract}
Background: The longitudinal tear or defect in the epithelial lining of the anal canal distal to the dentate line is called anal fissure. It is of two types: acute and chronic. The break in the cycle of pain, spasm and ischemia is essential for successful treatment of anal fissure. Among multiple non-surgical treatment approaches, the appropriate approach with good patient compliance might be the use of topical agents as chemical sphincterotomy. However, the effectiveness of these agents has not been evaluated widely.

Objectives: To evaluate clinical effectiveness of topical $0.2 \%$ glyceryl trinitrate, topical $2 \%$ diltiazem and their combination in the treatment of chronic anal fissure.

Methodology: The study was prospective comparative type including total 158 patients. Initially, they were given first line therapy followed by chemical sphincterotomy agents. The study drugs were given to 84 patients (three groups - $0.2 \%$ glyceryl trinitrate, $2 \%$ diltiazem and their combination) who were not healed after initial therapy. Patients were assessed for pain using visual analogue scale and other symptoms prior to and after two and six weeks of therapy.

Results: Complete healing rate was higher with combination (92.86\%) than individual agents. The reduction of visual analog scale score within each group and between the groups in the period between before and after treatment was found to be statistically significant. Headache and hypotension were the common side effects seen during study. Conclusion: Anal fissures can be successfully managed by chemical sphincterotomy. The topical nitrates and calcium channel blockers in combination are found to be effective choice rather than individual agents.
\end{abstract}

Key words: Anal Fissure; Chemical Sphincterotomy; Constipation; Pain; Sitz bath

DOI: https://doi.org/10.3126/jkmc.v8i3.29723

\section{INTRODUCTION}

A nal fissure or fissure in ano is a longitudinal tear or defect in the epithelial lining of the anal canal distal to the dentate line ${ }^{1}$. Though it is not a fatal condition,

Address for correspondence

Dr. Bikash Bahadur Rayamajhi

Assistant Professor, Department of Surgery,

Nepalese Army Institute of Health Sciences (NAIHS),

Sanobharyang, Kathmandu, Nepal

E-mail: drbikashrayamajhi@gmail.com

ORCID: https://orcid.org/0000-0001-8666-4761

ORCID: Anjan Khadka: https://orcid.org/0000-0002-1540-6316 Kabir Thakali: https://orcid.org/0000-0002-7624-0604 it can significantly influence the quality of life of the affected person due to its troubling symptoms such as severe pain and bleeding per rectum. Both genders are equally affected, with a slight predilection towards females ${ }^{2}$. Anal fissure are classified into two types: acute and chronic, based on symptoms, duration and per rectal examination findings. An acute fissure is a simple laceration of less than six weeks duration whereas a chronic anal fissure is an ulceration of more than six weeks duration characterized by presence of hypertrophied anal papilla, sentinel skin tag and exposed internal sphincter muscle fibers ${ }^{3}$. Healed anal fissure is defined as complete re-epithelialization of the tear or defect in anal canal. 
The treatment of anal fissure mainly aims at breaking the cycle of pain, spasm and ischemia. To minimize pain following anal trauma, all patients are initially managed with first line therapy in the form of stool softeners or bulk forming agents, topical 2\% lignocaine gel application and warm sitz baths for two weeks ${ }^{5}$. Any patients who do not achieve symptom relief with initial treatments can be prescribed with topical calcium channel blockers (nifedipine, diltiazem), or topical nitric oxide donors (glyceryl trinitrate) or botulinum toxin injection which is regarded as chemical sphincterotomy. Surgical management is instituted only in the treatment resistant or failure cases as it may lead to fecal incontinence ${ }^{6}$.

Though there are multiple non-surgical treatment approaches for anal fissure, the appropriate approach with good patient compliance might be the use of topical agents as chemical sphincterotomy. Various studies have shown that nitrate and calcium channel blockers are found to be effective as topical application. No single drug therapy has been proven superior as they show relatively poor healing rate when compared with surgical therapy which necessitates the investigation of combination drug therapies ${ }^{7}$. However, the effectiveness of these agents has not been evaluated widely ${ }^{8}$. The aim of this study is to evaluate the clinical effectiveness of chemical sphincterotomy i.e. topical $0.2 \%$ glyceryl trinitrate, topical $2 \%$ diltiazem and their combination in treatment of chronic anal fissure.

\section{METHODOLOGY}

This was a prospective comparative clinical study which involved 158 patients with diagnosis of anal fissure attending the surgical outpatient department (OPD) of tertiary level hospital of Central Nepal during the period from June 2018 to May 2019. Informed written consent was taken from patients before the commencement of the study after getting ethical approval from the institution.

A detailed history, general and systemic examination along with per rectal examination were done. Patient's age, gender, dietary habits, bowel habits and BMI were recorded as demographic variables. The new patients with anal fissure having symptoms more than six weeks duration who were treated with first line therapy for six weeks were included in the study. Patient with systemic diseases like diabetes mellitus, hypertension, chronic kidney or liver diseases, collagen tissue disease, malignancies, pregnancy, congestive cardiac failure, patients allergic to nitrates and diltiazem, patients with previous perineal surgery and immunocompromised patient or patient on immune suppressive therapy were excluded from the study.

All 158 patients diagnosed as anal fissure were initially treated with stool softeners or bulk forming agents, topical 2\% lignocaine gel and warm sitz baths for six weeks. Those patients with persistent symptoms for 10 minutes per session after initial therapy were randomly divided into three groups $(n=84)$ by stratified random sampling for chemical sphincterotomy viz. $0.2 \%$ glyceryl trinitrate (GTN) group ( $n=28), 2 \%$ diltiazem (D) group $(n=28)$ and their combination $(G T N+D)$ group $(n=28)$. All drugs were given topically twice a day for six weeks along with twice daily warm sitz bath and high fiber diet. Patients were assessed for pain and other related symptoms prior to and following two and six weeks of therapy. Pain was assessed using visual analogue scale (VAS) score ranging from 0 to 10,0 as no pain and 10 as worst pain imaginable. Effectiveness was also measured with relief of other symptoms and side effects of drug therapy. Statistical analysis was performed using graph pad prism 8.1. Analysis of variance and Brown Forsythe test were used for the comparison between the groups. A $p$ value of $<0.05$ was considered statistically significant.

\section{RESULTS}

The number of patients diagnosed as anal fissure in surgical OPD during 12 months duration was 158. After treating them with first line therapy i.e. warm sitz bath, stool softeners or bulk forming agents and topical 2\% lignocaine gel for six weeks, 74 (46.84\%) patients were healed whereas $84(53.16 \%)$ patients were not healed. Those 84 patients were randomly divided into three groups of twenty eight patients in each group to receive topical $0.2 \%$ glyceryl trinitrate, $2 \%$ diltiazem and their combination respectively.

The dietary habit pattern and body mass index (BMI) distribution of patients along with demographic profile are shown in table 1. The maximum number of patients in GTN group, D group and GTN+D group were 11 from 20 to 29 years age group, nine from 30 to 39 age group and eight from 20 to 29 age group respectively. The maximum number of patients from overall groups was 25 from 20 to 29 years age group. The number of male and female involved in the study were 36 and 48 respectively. The number of male in GTN, D and GTN+D group were 12,14 and 15 respectively whereas numbers of female were 16, 14 and 13 from each group respectively. 
The common symptoms presented by all patients were painful defecation $(n=158)$, per rectal $(P R)$ bleeding $(n=151)$, constipation $(n=136)$, perianal itching $(n=47)$ and perianal discharge $(n=12)$. The patterns of symptoms present after initial six weeks of therapy are shown in table 2. Overall reduction rate in per rectal bleeding and pain were $90.47 \%$ and $54.76 \%$ after six weeks of therapy. The reduction rate of per rectal bleeding and pain after six weeks of topical $0.2 \%$ glyceryl trinitrate therapy were $84.61 \%$ and $39.28 \%$ whereas with topical $2 \%$ diltiazem therapy were $88.46 \%$ and $53.57 \%$ and with their combination were $96.29 \%$ and $71.42 \%$ respectively.

The pain was assessed by observing the change in VAS score prior to and after therapy. VAS score showed that pain reduced by $\geq 50 \%$ in GTN, D and GTN+D group were $57.14 \%(n=16), 75 \%(n=21)$ and $92.85 \%(n=26)$ respectively. The average pain score prior to/ after six weeks of treatment were found to be $6.89 \pm 0.17 / 3.71 \pm 2.35,6.61 \pm 0.19 / 2.57 \pm 0.32$ and
$6.11 \pm 0.18 / 0.32 \pm 0.22$ in GTN, D and GTN+D groups respectively. The reduction of VAS score within each group and between the groups in the period between before and after treatment was found to be statistically significant (Table 3).

The number of patient with partial healing i.e.> 50\% reduction in VAS or VAS 1-3 and disappearance of symptoms in GTN and D groups were 16 and 21 respectively whereas 26 patients from GTN+D group showed complete healing (VAS=0). None of the patient with GTN and D groups showed complete healing. The numbers of non-healed patients were 12, seven and two from GTN, D and GTN+D groups respectively.

Following six weeks of treatment with glyceryl trinitrate, diltiazem and their combination, the common side effects observed were headache $(n=12)$, hypotension $(n=7)$ and gastrointestinal upset $(n=1)$ as shown in table 4.

\section{Table 1: Demographic Profile}

\begin{tabular}{llccc}
\hline Drugs & & GTN & D & GTN+D \\
\hline Age in years (Mean \pm SEM)) & & $34.4 \pm 1.42$ & $37.4 \pm 1.96$ & $32.93 \pm 1.40$ \\
Gender (Male:Female) & & $1.3: 1$ & $1.5: 1$ & $1.5: 1$ \\
& Normal & 7 & 6 & 9 \\
BMI & Overweight & 16 & 4 & 16 \\
& Obesity & 5 & 18 & 3 \\
Dietary Habits & Non-vegetarian & 21 & 24 & 25 \\
& Vegetarian & 7 & 4 & 3 \\
\hline
\end{tabular}

Table 2: Measurement of effectiveness

\begin{tabular}{|c|c|c|c|c|c|c|c|c|c|c|}
\hline \multirow[b]{2}{*}{ Symptoms } & \multirow{2}{*}{$\begin{array}{l}\text { After } 6 \text { wks } \\
\text { of first line } \\
\text { therapy } \\
(n=84)\end{array}$} & \multicolumn{3}{|c|}{ GTN Group $(n=28)$} & \multicolumn{3}{|c|}{ D Group $(n=28)$} & \multicolumn{3}{|c|}{ GTN+D Group $(n=28)$} \\
\hline & & Day 0 & $\begin{array}{c}\text { After } 2 \\
\text { wks }\end{array}$ & $\begin{array}{c}\text { After } 6 \\
\text { wks }\end{array}$ & Day 0 & $\begin{array}{c}\text { After } 2 \\
\text { wks }\end{array}$ & $\begin{array}{c}\text { After } 6 \\
\text { wks }\end{array}$ & Day 0 & $\begin{array}{c}\text { After } 2 \\
\text { wks }\end{array}$ & $\begin{array}{c}\text { After } 6 \\
\text { wks }\end{array}$ \\
\hline $\begin{array}{l}\text { Painful } \\
\text { defecation }\end{array}$ & 84 & 28 & 25 & 17 & 28 & 20 & 13 & 28 & 14 & 8 \\
\hline Bleeding PR & 79 & 26 & 14 & 4 & 26 & 18 & 3 & 27 & 10 & 1 \\
\hline $\begin{array}{l}\text { Perianal } \\
\text { itching }\end{array}$ & 0 & 0 & 0 & 4 & 0 & 0 & 3 & 0 & 0 & 1 \\
\hline $\begin{array}{l}\text { Perianal } \\
\text { discharge }\end{array}$ & 5 & 2 & 2 & 0 & 2 & 2 & 0 & 1 & 1 & 0 \\
\hline
\end{tabular}

Table 3: Visual Analogue Scale Score in different drug groups

$\begin{array}{lccccc}\text { Drugs } & \text { Before treatment } & \text { After } \mathbf{2} \text { weeks } & \text { After } \mathbf{6} \text { weeks } & \text { ANOVA } & \text { Brown-Forsythe Test } \\ \text { Glyceryl trinitrate } & 6.893 \pm 0.1654 & 4.643 \pm 0.2071 & 2.643 \pm 0.4431 & & \mathrm{~F}=14.34 \\ \text { Diltiazem } & 7.345 \pm 0.1879 & 5.276 \pm 0.2492 & 2.2827 \pm 0.4176 & \mathrm{P}<0.0052 & \mathrm{P}=0.8128 \text { (ns) } \\ \text { Combination } & 6.107 \pm 0.1806 & 2.679 \pm 0.2827 & 0.8214 \pm 0.2245 & & \end{array}$


Table 4: Side effect of the treatment

\begin{tabular}{lccc} 
Side effects & GTNGroup $(\mathbf{n = 2 8 )}$ & D Group $(\mathbf{n = 2 8 )}$ & GTN+D Group (n=28) \\
Headache & $7(25 \%)$ & $2(17.14 \%)$ & $3(10.71 \%)$ \\
Hypotension & $2(7.14 \%)$ & $2(7.14 \%)$ & $3(10.71 \%)$ \\
Gastrointestinal upset & 0 & 0 & $1(3.57 \%)$ \\
\hline
\end{tabular}

\section{DISCUSSION}

Anal fissure is one of the common benign ano-rectal problems presenting to the surgical outpatient department. Anal fissure develops in approximately $10-15 \%$ of the patients presenting with proctologic discomfort. The treatment of chronic anal fissure has shifted in the recent years from surgical to medical modalities because of disability and the risk of incontinence associated with surgery. Anal fissure was found to be common in young adults (20 to 29 years age groups) which is similar to study done in India9. Our study has shown that $57.14 \%$ and $42.86 \%$ were male and female respectively. Our study showed slight male preponderance in occurrence of anal fissure which is in contrast to Shrestha SK et al and in coherence to the findings of Kuiri SS et al. and Giridhar CM et $a^{2}{ }^{2,10,11}$.

Our study demonstrated that non-vegetarian diet, overweight and constipation were present in patients of anal fissure. Non-vegetarian diet has less fiber content which may predispose to constipation. Straining during defecation is common in constipation which leads to tear in the soft friable anal mucosa leading to anal fissure. Similarly, anal fissures are common in overweight population due to inadequate fiber intake, decreased physical activity and prolonged sitting, thereby leading to high basal internal sphincter tone and poor blood flow 7,8 .

In our study, $46.84 \%$ of the patients with anal fissure were successfully treated with first line therapy i.e. warm sitz bath, stool softeners or bulk forming agents and topical $2 \%$ lignocaine gel. The common symptoms they presented with were painful defecation (100\%) followed by per rectal bleeding (95.57\%), constipation (86.07\%), perianal itching $(29.74 \%)$ and perianal discharge $(7.56 \%)$. Perianal itching was completely relieved and pain and bleeding was reduced by half after six weeks of first line therapy with warm sitz bath, stool softeners or bulk forming agents or topical lignocaine gel application ${ }^{12}$. Fissures are likely to be related to local trauma following passage of hard stool, chronic constipation and straining during bowel movements. Stool softeners helps to hydrate and soften the fecal material whereas bulk forming agents add bulks and water to stool facilitating natural defecation. Similarly, warm sitz bath improves local hygiene, reduce inflammation and promote blood flow at the ulcer site whereas $2 \%$ lignocaine gel application helps to relieve the pain, itching and burning associated with anal fissure.

Out of 158 patients, 84 patients who remained symptomatic after first line therapy were candidates for comparative study comprising of three groups. All three groups showed partial alleviation of symptoms like pain, bleeding and constipation whereas complete alleviation of perianal discharge after six weeks of therapy. The patients receiving topical $0.2 \%$ glyceryl trinitrate showed $61.65 \%$ reduction in VAS score from day 0 (i.e. before starting treatment) to 6 weeks following treatment. Similarly, the patients receiving topical $2 \%$ diltiazem showed $68.93 \%$ decrement in VAS score whereas patient receiving topical $0.2 \%$ glyceryl trinitrate and $2 \%$ diltiazem in combination showed $86.54 \%$ reduction in VAS score from day 0 to six weeks after the treatment which is similar to the study done by Bulus $\mathrm{H}$ et $\mathrm{al}^{8}$. The change in VAS score before and after treatment with glyceryl trinitrate, diltiazem and their combination is found to be statistically significant $(p=0.0052)^{13}$. The symptomatic relief was seen more with combination therapy rather than individual drug therapy. This might be due to synergistic effect of two commonly used agents i.e. glyceryl trinitrate and diltiazem which are already proven effective agents for chemical sphincterotomy. Persistence of anal sphincter spasm and the ischemia after tear in the epithelial lining of anal canal leads to chronic anal fissure. The aim of chronic anal fissure treatment is to remove ischemia by reducing spasm of anal sphincter. Various surgical and medical treatments have been tried for healing anal fissure. Chemical sphincterotomy have been suggested as an alternative to surgery to avoid possible complications of surgical treatment. Among these, nitrates, calcium channel blockers, and botulinum toxin are the most studied and used agents. Nitroglycerin, which is locally metabolized to nitric oxide, promotes fissure healing by decreasing anal sphincter pressure and concurrently increasing ano-dermal blood flow. Similarly, diltiazem is a calcium channel blockers which inhibits muscle contraction by preventing calcium influx into the cytoplasm via 
membrane channels, thus causing relaxation of anal sphincter and increasing ano-dermal blood flow ${ }^{13}$.

Complete healing rate after six weeks of combination (GTN+D) therapy was $92.86 \%$ whereas there was no complete healing in six weeks when drugs were applied as individual therapy. Partial healing rate after individual drug application with GTN and D were $57.14 \%$ and $75 \%$ respectively. Non-healing rates were $42.86 \%, 25 \%$ and 7.14\% for GTN, D and GTN+D groups respectively. A systematic review done by Poh $A$ et al. showed healing rates for topical glyceryl trinitrate and diltiazem from $40.4 \%$ to $68 \%$ and $67 \%$ to $89.4 \%$ respectively ${ }^{7}$. There are various studies with topical diltiazem application among patients who are glyceryl trinitrate treatment resistance cases showing improvement in almost $50 \%$ cases. This could be due to its tolerance being higher than and mechanism of action being different from those of nitrates. Hence healing rates is higher among patients receiving combination drugs. Though first line medical therapy cures most anal fissures, chemical sphincterotomy with glyceryl trinitrate and diltiazem remains standard mode of treatment in chronic anal fissures ${ }^{8,14}$. However, these drugs as individual therapy and in combination are not devoid of side effects such as headache, perianal itching, hypotension and gastrointestinal upset which may restrict its use by decreasing patient compliance ${ }^{15-17}$. A common

\section{REFERENCES}

1. Feingold DL, Lee-Kong SA. "Anal Fissure and Anal Stenosis." Fundamentals of Anorectal Surgery. Springer, Cham, 2019. 241-55. [DOI]

2. Shrestha SK, Thapa PB, Maharjan DK, Tamang TY. Effectiveness of $0.2 \%$ glyceryl trinitrate and $0.5 \%$ nifedipine in the treatment of chronic anal fissure. J Nepal Med Assoc 2017;56(205):149-52. [FullText]

3. Tavakoli-Dastjerdi S, Motavasselian M, Emami SA, Mansourian M, Sahebkar A, Teimouri A. Efficacy of a combination of herbal gel versus topical diltiazem (2\%) in chronic anal fissure healing: a randomized double-blind clinical trial. Journal of Herbmed Pharmacology. 2019 Apr;8(2):139-45. [DOI]

4. Pastar I, Stojadinovic O, Yin NC, Ramirez H, Nusbaum AG, Sawaya A et al. Epithelialization in Wound Healing: A Comprehensive Review. Adv Wound Care (New Rochelle). 2014;3(7):445-464. [DOI]

5. Șurlin V, Scurtu S. Conservative treatment for anal fissure-for how long?-review of the literature and personal experience. Facta Universitatis, disadvantage of chemical sphincterotomy is nonpermanent effect of sphincter relaxation resulting in high recurrence rate between 10 to $50 \%$ on long term follow up ${ }^{7}$.

Headache and hypotension were the main side effects occurring in almost 30\% patients using topical glyceryl trinitrate application whereas almost 25\% among patients using topical diltiazem brought about by its vasodilatation effect ${ }^{8,9}$. Topical diltiazem is associated with fewer side effects, probably because of minimal systemic absorptions ${ }^{8}$. Gastrointestinal upset like nausea, vomiting and loose stool was seen in one patient with combination treatment only ${ }^{18,19}$.

The significance of this study would have been better if it was conducted in multi-center with larger sample size, positive control group and longer duration including the follow up period and recurrence rate.

\section{CONCLUSION}

Anal fissures are common ano-rectal problem encountered in surgical OPD. Chemical sphincterotomy is found to be effective armamentarium against chronic anal fissures. The combination of topical nitrates and calcium channel blockers seem effective option rather than individual agents though further effectiveness study is needed.
Series: Medicine \& Biology. 2019 Jan 2;21(1):7-11. [FullText]

6. Dey D, Pai G. Prospective comparative study between lateral sphincterotomy and subcutaneous fissurectomy with topical $2 \%$ diltiazem gel in the treatment of chronic anal fissure. International Surgery Journal. 2019 Jun 29;6(7):2571-5. [DOI]

7. Poh A, Tan KY, Seow-Choen F. Innovations in chronic anal fissure treatment: A systematic review. World Journal of Gastrointestinal Surgery. 2010 Jul;2(7):23141. [PubMed]

8. Bulus H, Varol N, Tas A, Coskun A. Comparison of topical glyceryl trinitrate, topical diltiazem and their combination in the treatment of chronic anal fissure. Asian Journal of Surgery.2013;36:165-9. [PubMed]

9. Sajith BSM, Gupta R, Singh L. Effectiveness of conservative management of acute anal fissure: a prospective clinical study of 165 patients. International Surgery Journal.2017 Sep;4(9):3028-33. [DOI]

10. Kuiri SS, Saha AK, Mandal N, Ghosh G, Mandal N, Ghosh B et al. Comparative study of lateral 
sphincterotomy versus local $2 \%$ diltiazem ointment for the treatment of chronic anal fissure. IOSR-JDMS. 2014;13(6):36-40. [DOI]

11. Giridhar CM, Babu P, Rao KS. A comparative study of lateral sphincterotomy and $2 \%$ diltiazem gel local application in the treatment of chronic fissure ano. J Clin Diagn Res. 2014 Oct; 8(10): NC01-NC02. [PubMed]

12. Zghair LF. Diltiazem Gel $2 \%$ in treatment of acute anal fissure. The Pharma Innovation. $2016 \mathrm{Nov}$ 1;5(11, Part A):22. [FullText]

13. Alvandipour M, Ala S, Khalvati M, Yazdanicharati J, Koulaeinejad N. Topical Minoxidil Versus Topical Diltiazem for Chemical Sphincterotomy of Chronic Anal Fissure: A Prospective, Randomized, DoubleBlind, Clinical Trial. World journal of surgery. $2018 \mathrm{Jul}$ 1;42(7):2252-8. [PubMed]

14. Motie MR, Hashemi P. Chronic Anal Fissure: A comparative study of medical treatment versus surgical sphincterotomy. ActaMedicalranica. 2016 Jul 9:437-40. [DOI]

15. Schlichtem Hall G, Kann BR. Anal Fissure. In Anorectal Disease 2016 (pp. 95-126). Springer, Cham. eier S,
Engel A. Anal fissure. Australian prescriber. 2016 Feb;39(1):14. [DOI]

16. Razack A, Raj VN. Comparison between lateral internal anal sphincterotomy and diltiazem in the treatment of chrnic anal fissure. Journal of Evolution of Medical And Dental Sciences-JEMDS. 2015 Feb 23;4(16):2700-5. [FullText]

17. Essani R, Papaconstantinou HT. Fissure-in-Ano. InShackelford's Surgery of the Alimentary Tract, 2 Volume Set 219 Jan 1 (Page no. 1864-1870).

18. Bohl JL, Herline AJ. Surgery and nonoperative therapy of anal fissure. In: Whitlow CB, Beck DE, Margolin DA, Hicks TC, Timmcke AE, editors. Improved Outcomes in Colon and Rectal Surgery. First Edition. Colchester UK. Informa Healthcare. 2010. p. 199-214.

19. Arroyo A, Montes E, Calderón T, Blesa I, Elía M, Salgado $G$ et al. Treatment Algorithm for Anal Fissure. Consensus Document of the Spanish Association of Coloproctology and the Coloproctology Division of the Spanish Association of Surgeons. Cirugía Española (English Edition). 2018 May;96(5):260-7. [PubMed] 